The general survey of the work of the African Studies Program is followed by appendices listing Ph.D.s from 1939 to 1970 ; students undertaking dissertation research 1970-I; subjects and status of Ph.D. dissertations, October 1970; Fellowships 1970-1; and Courses with African content $1969-70$.

Copies of the report may be obtained from the Program of African Studies, Northwestern University, 1813 Hinman Avenue, Evanston, Illinois.

\title{
Research Conference: Afro-American Societies and Cultures
}

Tre U.S. Social Science Research Council committee, under the chairmanship of Sidney W. Mintz, held its first research conference, on continuities and discontinuities in AfroAmerican societies and cultures, on 2-4 April 1970 at the University of the West Indies, Jamaica, with the aid of the Wenner-Gren Foundation for Anthropological Research. The first session was on Afro-American societies and cultures in hemispheric perspective; the second on social organization; the third on religious behaviour; and the fourth on languages and socio-linguistics. Details of the papers presented may be found in Items, vol. 24, no. 3, September 1970, pp. 30-1.

\section{Conference on Urban Growth in Black Africa and Madagascar, ig September- 2 October 1970, at Talence, France}

Thrs Conference, sponsored by the Centre National de la Recherche Scientifique in conjunction with ORSTOM, was undertaken by the Centre d'Études de Géographie Tropicale at the University of Bordeaux at Talence. The Centre provided an excellent setting for a meeting of over Ioo geographers and other social scientists under the Presidency of Professor Pierre Gourou, the doyen of francophone gengraphers of the tropics. The Conference was addressed by Professor Jacqueline Beaujeu-Garnier on ' Urban Growth in Tropical Lands'. Papers which had been invited had previously been made available to Conference participants and provided the background for the remainder of the proceedings. Fourteen major topics were presented for discussion and each of these was introduced by a general report. They ranged widely and included the facts and processes of urban growth, differentiation in urban societies, the tole of industry and handicrafts, problems of employment, urban typology and morphology, inter- and intra-urban relations, and the health of immigrants in towns. For the most part there was a lack of satisfactory conceptual frameworks into which the detailed material might be fitted. For example, while a great deal of information was presented on various towns, particularly in francophone Africa, little emerged in respect of similarities and differences among them. To some extent this lack of conceptual framework was compensated for in the discussions. The Conference provided an opportunity for renewing contacts and for making a large number of new ones, particularly with many French, Belgian and francophone African colleagues for the smaller number of geographers from elsewhere. There were representatives from anglophone Africa, from Germany, U.K., and U.S.A. Apart from the academic activities of the meeting, participants enjoyed the hospitality of CNRS and the University and City of Bordeaux. Both the academic and social arrangements were admirably organized and conducted by Professor Guy Lasserre, Director of the Centre d'Études de Géographie Tropicale, ably seconded by Professor Pierre Vennetier, and supported by other colleagues. The papers submitted to the Conference, together with introductory statements and subsequent discussions, will be published in due course by CNRS.

(Communicated by Dr. R. Mansell Prothero) 